\title{
PHYLOGENETIC ANALYSIS OF THE HUMAN THYROID-STIMULATING HORMONE
}

\author{
Maristella de Araújo Carvalho Sousa*, Raymundo Paraná**, Luís Jesuíno de Oliveira Andrade* \\ Corresponding author: Luís Jesuíno de Oliveira Andrade - luis_jesuino@yahoo.com.br \\ * Health Department, Post Graduation Program in Health Sciences, State University of Santa Cruz, Ilhéus - Bahia - Brazil. \\ ** Medicine Department, Federal University of Bahia, Salvador - Bahia - Brazil.
}

\begin{abstract}
Background: Thyroid-stimulating hormone (TSH) is a member of the vertebrate glycoprotein hormone family [1]. It's secreted from pituitary cells as heterodimers composed of an alpha and a beta- subunit. The thyrotrophic cells that secrete TSH are preferentially located in the anteromedial and anterolateral portions of the pituitary. Objective: We performed a phylogenetic analysis of the TSH, and phylogram of the maximum likelihood relations between TSH coding sequences of five representative species. Methods: We extracted the available DNA and protein sequences for TSH from the NCBI databank. Searched for regions presenting sequence similarities to the constituent domains of TSH - alpha and beta-subunits - with the Blastall command ftp://ftp.ncbi.nlm.nih.gov/blast/db/ website, pairs of sequences were compared on the basis of their global alignment with the Myers \& Millers algorithm manpages.ubuntu. $\mathrm{com} / \mathrm{manpages} / \mathrm{karmic} / \mathrm{man}$, and the phylogenetic reconstructions were performed online by using a maximum likelihood method with PhyMy 3.0 software on the website file (http://www.phylogeny. $\mathrm{fr} /$ ). Results: The comparison of the phylogenetic trees that we obtained compared with those studies previously published revealed similar subclusters with high protein homology. Conclusion: This study demonstrates that human TSH is structurally related to TSH of the species analysed, Bos taurus, Mus musculus, Canis lupus familiaris, and Cyprinus carpio, respectively.
\end{abstract}

Keywords: Thyroid-stimulating hormone; Phylogenetic analysis; Homology; Gene structure.

\section{INTRODUCTION}

Thyroid-stimulating hormone (TSH) is a member of the vertebrate glycoprotein hormone family. ${ }^{(1)}$ It is a heterodimeric $28-\mathrm{kDa}$-glycoprotein hormone released from the anteromedial and anterolateral portions of the pituitary gland and is a regulator of thyroid function. The synthesis of TSH is controlled by the hypothalamic neuropeptide TSH-releasing hormone, and normal human 
TSH molecule contains an alpha-subunit with two oligosaccharide chains and a beta-subunit with one oligosaccharide chain. Each subunit contains a terminal sialic acid and a sulfate residue that confer TSH binding and biological activity. ${ }^{(2)}$ The alpha and beta subunits of TSH have functionally important domains associated with $\mathrm{TSH}$ receptor binding and activation.
The human TSH protein structure has been studied in detail (Figure 1). The TSH alphasubunit gene is composed of a 92-amino acids protein, and the coding sequence of the TSH betasubunit gene predicts an 118-amino acid protein. (3) Human pituitary TSH oligosaccharides are complex-type structures and end predominantly with $\mathrm{SO}_{4} 4 \mathrm{GalNAc}\left(\beta_{1-4}\right) \mathrm{GlcNAc}_{1}$ but also with $\operatorname{NeuAc}(\alpha 2-3$ or $\alpha 2-6) \mathrm{Gal}(\beta 1-4)$ GlcNAc $\beta$ 1. ${ }^{(4)}$

Figure 1 - Structure of the human Thyroid-stimulating hormone protein

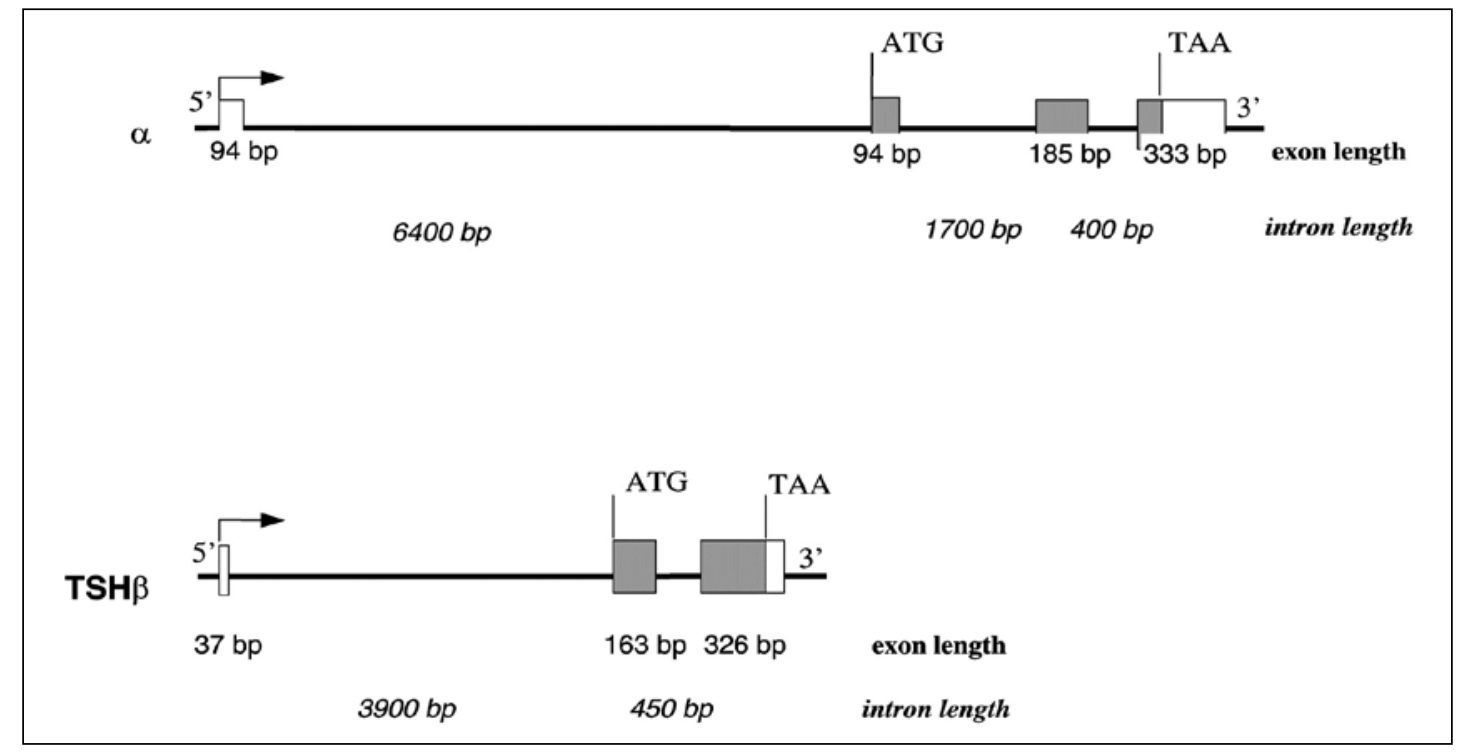

Source: Mariusz W. Szkudlinski et al. Physiol Rev. 2002;82:473-502

The TSH is a regulator of thyroid function. An increase or decrease of TSH defines the thyroid hormone concentrations. In humans, mice and fish, thyroid hormone levels determine the basal rate of metabolism and overall energy expenditure. (5) In other species, such as Senegalese sole, ${ }^{(6)}$ amphibians, ${ }^{(7)}$ urochordateas, $^{\left({ }^{(8)}\right.}$ amphioxus ${ }^{(9)}$ and lamprey, ${ }^{(10)}$ thyroid hormones play a critical role in the metamorphosis from larvae to juveniles.

Many studies have used bioinformatics tools to analyze the evolution of proteins and genes, and such tools may be useful in this context. ${ }^{(1)}$ Phylogenetic analyses based on molecular tools are helpful to distinguish the origin of species, understand and clarify their evolutionary history, and provide a genetic basis. We conducted a phylogenetic analysis of the TSH human molecule and compared it with the genome sequences of other vertebrates.

\section{MATERIALS AND METHODS}

\section{SEQUENCE EXTRACTION}

We extracted the available DNA and protein sequences for TSH from the NCBI databank (http:// www.ncbi.nlm.nih.gov) website for five species: human [GenBank:AAA36782.1, GenBank:AAB05845.1, GenBank:AAA61235.1], Mus musculus [GenBank:AAA40494.1, GenBank:AAA96700.1], Bos taurus [GenBank: AAA30796.1], Canis lupus familiaris [GenBank: AAD42900.1], Cyprinus carpio [Gen- 
Bank: BAA20082.1]. We first translated the DNA sequence to obtain a putative amino-acid sequence.

\section{SEQUENCE HOMOLOGY}

We searched for regions presenting sequence similarities to the constituent domains of TSH alpha- and beta-subunits - with the Blastall command (ftp://ftp.ncbi.nlm.nih.gov/blast/db/) website, version 2.2.19. Pairs of sequences were compared on the basis of their global alignment with the Myers \& Millers algorithm manpages.ubuntu.com/ manpages/karmic/manı. Results were generated in a separate text file containing alignment diagrams, scores, degrees of identity, similarity, and gaps. We used ClustalX software (ftp://ftpigbmc.u-strasbg. $\mathrm{fr} /$ pub/ClustalX/) website for analysis of multiple alignments of three or more sequences. The results were exported to a separate text file, but without information about the score, because it was not possible to use more than two sequences for score calculation with Compositional Matrix Adjust.

\section{PHYLOGENETIC ANALYSIS}

Phylogenetic analysis based on molecular tools is helpful to distinguish the origin of species, understand and clarify their evolutionary history, and provide a genetic basis for selective study.

The phylogenetic reconstructions were performed online using a maximum likelihood method with
PhyMyL 3.0 software $^{(12)}$ on the website file (http:// www.phylogeny.fr/). A range of analyses, from simple $p$ distance to multiparameter models with gamma correction, were used. The significance of the phylogenetic tree was assessed by bootstrapping, with 500 iterations. The Jones-Taylor- Thornton (JTT) model of amino-acid sequence evolution, with gamma correction, was used for distance estimation. ${ }^{(13)}$ In each case, the distance was validated with 500 bootstrap replications.

Mapping the genomic neighborhoods of TSH genes was performed with region overview on $\mathrm{NCBI}$ genome browsers.

\section{GENE STRUCTURE}

The gene structure was performed on-line by SWISSMODEL using website file (http://swissmodel. expasy.org/). SWISS-MODEL is a fully automated protein structure homology modelling server. The purpose of this server is to make Protein Modelling accessible to molecular biologists worldwide.

\section{RESULTS}

The comparison of human TSH protein sequences GenBank:AAA36782.1, AAB05845.1, and GenBank:AAA61235.1 with Mus musculus, Bos taurus, Canis lupus familiaris, and Cyprinus carpio indicated protein similarities of $86 \%, 89 \%, 50 \%$, and $47 \%$ respectively (Figure 2 ).

Figure 2 - Proteic homologies between GenBank: AAA36782.1 and: GenBank: AAA40494.1, GenBank: AAA30796.1, GenBank: AAD42900.1, GenBank: BAA20082.1.

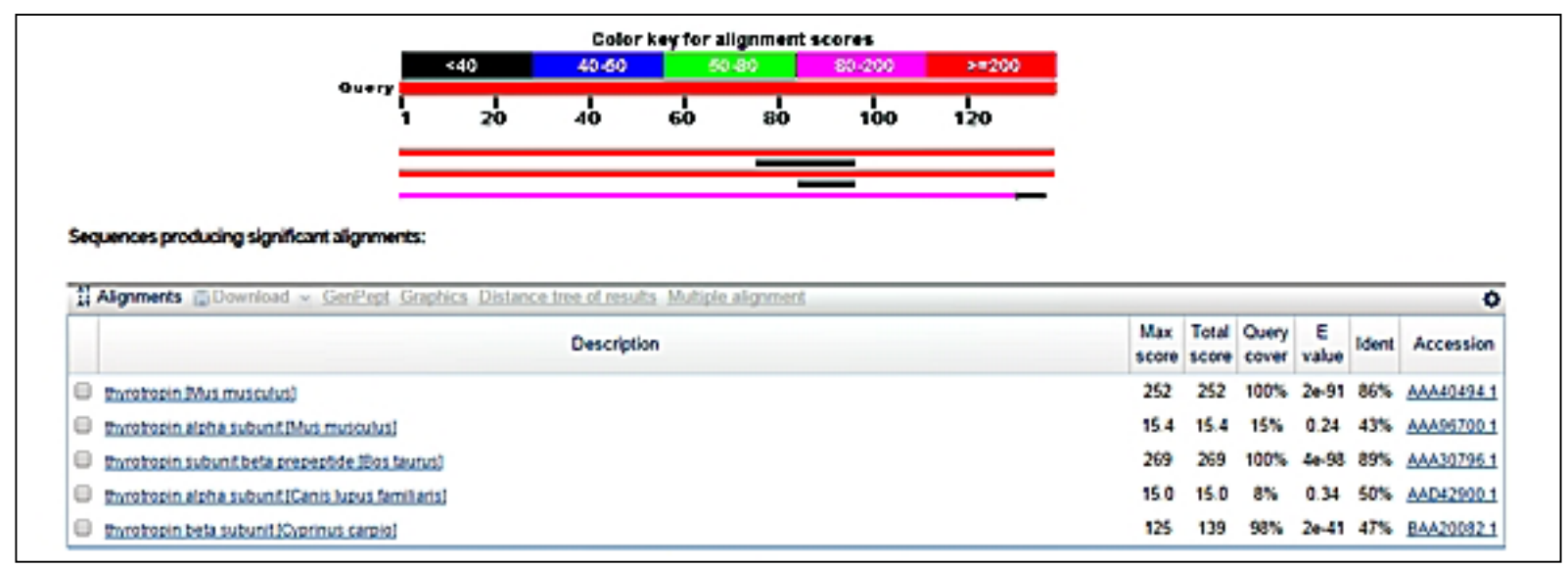


We performed a phylogenetic analysis of the TSH (Figure 3), and phylogram of the maximum likelihood relationships between TSH coding sequences of five representative species.

Figure 3 - Phylogenetic analysis of the TSH

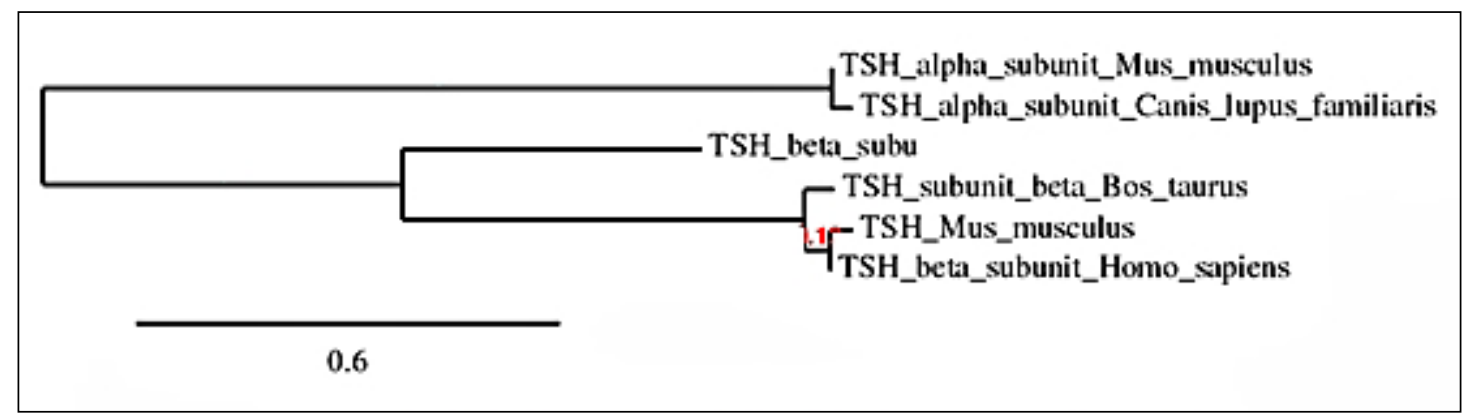

\section{THYROTROPIN BETA SUBUNIT [HOMO SAPIENS]}

The human TSH beta-subunit gene structure had 4.5 kilobases $(\mathrm{Kb})$ in size and it was separated into three exons. Primer extension analysis has one transcription starting point and S1 mapping analysis with two blocks of polyadenylation sites in normal pituitaries. The 5'-flanking region contained two 'TATA' boxes, two 'CAAT' boxes, and two sequences similar to the cyclic AMP-responsive elements (Figure 4). ${ }^{(14)}$

Figure 4 - The human TSH beta-subunit gene structure

\section{THYROTROPIN [MUS MUSCULUS]}

The mouse TSH beta-subunit gene structure had $4.8 \mathrm{~Kb}$ in length and contained five exons, which are 27, 47, 41, 163, and 328 base pairs long. Exons 1, 2, and 3 encode only 5 '-untranslated mRNA sequences and were separated by introns that were 150 and 380 base pairs long. The protein-coding mRNA sequences were found in exons 4 and 5 , and they were interrupted by a 460 -base pair intron. The position of this intron, between the codons for amino acids 34 and 35 , has been conserved in all known glycoprotein subunit genes of hormone beta. A large 3.2-Kb intron separated exons 3 and 4. Each start site in the mouse gene was flanked by characteristic TATAA box and CAAT box sequences (Figure 5). ${ }^{(15)}$ 
Figure 5 - The mouse TSH beta-subunit gene structure

Mode1_01 MSAAVLLSVLFALACGQAASFCIPTEYTMYVDRRECAYCLTINTTICAGYCMTRDINGKLFLPKYALSQD 70

4ay9.1.B-- - - - - - - - - SCEITNITIAIE EE ECISINTTWCAGYCYTBDLVYKD--PARERIQK 49

Model_01 VCTYRDFIYRTVEIPGCPHHVTPYFSFPVAVSCKCGKCNTDNSDCIHEAVRTNYCTKPQSFYLGGFSV 138

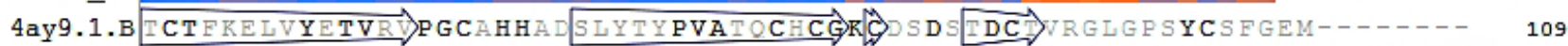

\section{THYROTROPIN SUBUNIT BETA [BOS TAURUS]}

The beta subunit of bovine TSH gene structure had 35 nucleotides from the 5' untranslated region of thyrotropin beta subunit mRNA and 60 nucleotides coding for an $\mathrm{NH}_{2}$-terminal precursor segment. This was followed by 339 nucleotides that code for the published amino acid sequence of the thyrotropin beta subunit. Following the 339 nucleotide beta subunit coding sequence, no termination codon was encountered for another 15 nucleotides. Thus, the cDNA codes for a thyrotropin beta subunit contain an additional 5 amino acids at the $\mathrm{COOH}$ terminus. The cDNA also contained 82 nucleotides of 3 ' untranslated sequence followed by a short poly $(\mathrm{A})$ segment. The $\mathrm{NH}_{2}$-terminal peptide is a signal peptide. The possible significance of the additional amino acids at the $\mathrm{COOH}$ terminus is not clear, but they are essential for the biological activity of TSH-beta (Figure 6). ${ }^{(16)}$

Figure 6 - The beta subunit of bovine TSH gene structure

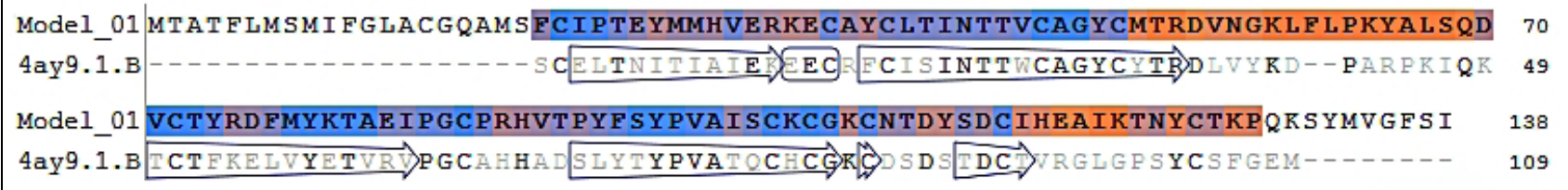

THYROTROPIN ALPHA SUBUNIT [CANIS LUPUS FAMILIARIS]

The alpha subunit of canine TSH gene structure had a sequence of 96 amino acid matures, and a sequence encoding a 24 amino acid signal peptide. The analysis showed that the canine alpha subunit TSH potentially contained five disulfide bonds and two oligosaccharide chains $\mathrm{N}$-linked to Asn residues located at positions 56 and 82 (Figure 7). ${ }^{(17)}$

Figure 7 - The alpha subunit of canine TSH gene structure 


\section{THYROTROPIN BETA SUBUNIT [CYPRINUS CARPIO]}

The beta subunit of carp TSH gene structure had a sequence of 19 amino acid residues and a mature TSH beta subunit protein of 131 residues. The full- length sequence consisting of 3 ' and 5' untranslated regions had 585 bp long. Oligonucleotide primers were designed from the sequenceof the common carp carp. The full-length sequence was then obtained by 3' and 5' rapid amplification of CDNA ends (Figure 8$).{ }^{(18)}$

Figure 8 - The beta subunit of carp TSH gene structure

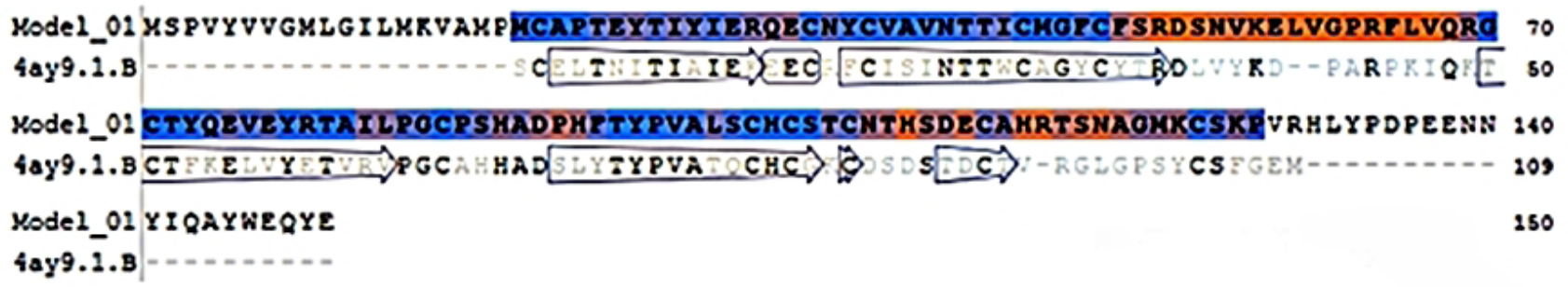

\section{DISCUSSION}

The present study investigated phylogenetic relationships between human TSH sequence and TSH coding sequences of five other significant species. Each one of the five species shows significant bootstrap value in support of a phylogenetic relationship to the human TSH. The results indicate that the species share a common evolutionary trait.

The human TSH is a member of the glycoprotein hormone family derived from heterodimerization of a common $\alpha$ subunit with hormone-specific beta subunits. The genes encoding the common alpha subunit with hormone-specific beta subunits are present as single copies and in humans are located on chromosomes 6 and 1, respectively. TSH is essential for the production of iodothyronines by the thyroid gland and disorders of the pituitary-thyroid gland-thyroid hormone axis lead to disturbances of essentially all metabolic pathways and organs. ${ }^{(19)}$

The structure of the human TSH-beta gene is very similar to the previously characterized TSHbeta genes from mice. ${ }^{(20)}$ In mice, the TSH-beta subunit gene is localized on chromosome $3{ }^{(21)}$ The comparison of our phylogenetic trees with those obtained in previously published studies revealed similar subclusters with high protein homology.

The humans are closer to mice than to cows, cows and humans have sufficient DNA sequence similarity to enable us to map the human genome almost entirely onto cow. Previous studies based on mapping data showed that human and cows have approximately 201 homologous blocks of DNA. ${ }^{(22)}$ Regarding the similarity between the human TSH and the Bos taurus TSH protein, in the present study BLAST searches of the GenBank database confirmed the Bos taurus TSH protein is highly similar to human TSH. When the TSH subunit beta [Bos taurus] sequence was used as a query our study presented $89 \%$ of similarity with the thyrotropin beta subunit [Homo sapiens] protein.

The domestic dog, Canis lupus familiaris, is a useful model organism for genetic, physiological, and behavioral studies. The gene encoding the TSH beta subunit of canine was already cloned from the canine genomic DNA by direct polymerase chain reaction using primers that were designed based on the consensus sequences from other species. (23) Regarding the similarity between TSH human 
and TSH alpha subunit [Canis lupus familiaris], our study with BLAST searches of the GenBank database confirmed that the Canis lupus familiaris TSH protein is relatively similar to TSH human.

In common carp [Cyprinus carpio] the functional endocrine thyroid is associated with renal tissues. (24) Comparison of the structure of the TSH subunit beta [Homo sapiens] with the fish protein shows that the TSH subunit beta [Homo sapiens] is almost the same ${ }^{(25)}$. In our study, the phylogenetic tree constructed from amino acid sequences suggest a closer relationship between the TSH human and carp [Cyprinus carpio].

In conclusion, this study demonstrates that human TSH is structurally related to TSH of the species analysed Bos taurus, Mus musculus, Canis lupus familiaris and Cyprinus carpio, respectively.

\section{REFERENCES}

1. Pierce JG, Parsons TF. Glycoprotein hormones: structure and function. Annu Rev Biochem. 1981;50:465-495.

2. Grossmann M, Weintraub BD, Szkudlinski MW. Novel insights into the molecular mechanisms of human thyrotropin action: structural, physiological, and therapeutic implications for the glycoprotein hormone family. Endocr Rev. 1997;18(4):476-501.

3. Wondisford FE, Usala SJ, DeCherney GS, Castren M, Radovick S, Gyves PW, et al. Cloning of the human thyrotropin beta-subunit gene and transient expression of biologically active human thyrotropin after gene transfection. Mol Endocrinol. 1988;2(1):32-9.

4. Hiyama J, Weisshaar G, Renwick AG. The asparagine-linked oligosaccharides at individual glycosylation sites in human thyrotrophin. Glycobiology. 1992;2(5):401-9.

5. Power D, Llewellyn L, Faustino M, Nowell M, Björnsson B, Einarsdottir I, et al. Thyroid hormones in growth and developement of fish. Comp Biochem Physiol C Toxicol Pharmacol. 2001; 130(4):447-59.
6. Manchado M, Infante C, Asensio E, Planas J, Canavate J. Thyroid hormones down-regulate thyrotropin beta subunit and thyroglobulin during metamorphosis in the flatfish Senegalese sole (Solea senegalensis Kaup). Gen Comp Endocrino. 2008;155(2):447-55.

7. Tata J. Amphibian metamorphosis as a model for the developmental actions of thyroid hormone. Mol Cell Endocrinol. 2006;246(12):10-2O.

8. Patricolo E, Cammarata M, D'Agati P. Presence of thyroid hormones in ascidian larvae and their involvement in metamorphosis. J Exp Zool. 2001;290(4):426-30.

9. Paris $M$, Laudet $\mathrm{V}$. The history of developmental stages: metamorphosis in chordates. Genesis. 2008; 46(11):657-72.

1O. Manzon R, Holmes J, Youson J. Variable effects of goitrogens in inducing precocious metamorphosis in sea lampreys (Petromyzon marinus). J Exp Zool. 2001;289(5):290-303.

11. Rigden D, Mosolov V, Galperin M. Sequence conservation in the chagasin family suggests a common trend in cysteine proteinase binding by unrelated protein inhibitors. Protein Sci. 2002;11(8):1971-7.

12. Dereeper A, Guignon V, Blanc G, Audic S, Buffet $S$, Chevenet $F$, et al. Phylogeny.fr: robust phylogenetic analysis for the non-specialist. Nucleic Acids Res. 2008;36(Web Server issue):W465-9.

13. Jones D, Taylor W, Thornton J. A mutation data matrix for transmembrane proteins. FEBS Lett. 1994;339(3):269-75.

14. Tatsumi K, Hayashizaki Y, Hiraoka Y, Miyai $\mathrm{K}$, Matsubara K. The structure of the human thyrotropin beta-subunit gene. Gene. 1988;73(2):489-97.

15. Wolf O, Kourides IA, Gurr JA. Expression of the gene for the beta subunit of mouse thyrotropin results in multiple mRNAs differing in their 5'-untranslated regions. J Biol Chem. 1987;262(34):16596-603.

16. Maurer RA, Croyle ML, Donelson JE. The sequence of a cloned cDNA for the beta subunit of bovine thyrotropin predicts a protein 
containing both $\mathrm{NH}$-and $\mathrm{COOH}$-terminal extensions. J Biol Chem. 1984;259(8):5024-7.

17. Yang X, McGraw RA, Ferguson DC. cDNA cloning of canine common alpha gene and its co-expression with canine thyrotropin beta gene in baculovirus expression system. Domest Anim Endocrinol. 2000;18(4):379-93.

18. Chatterjee A, Hsieh YL, Yu JY. Molecular cloning of cDNA encoding thyroid stimulating hormone beta subunit of bighead carp Aristichthys nobilis and regulation of its gene expression. Mol Cell Endocrinol. 2001;174(1-2):1-9.

19. Paschke R, Ludgate $M$. The thyrotropin receptor in thyroid diseases. $N$ Engl J Med. 1997;337(23):1675-81.

2O. Guidon PT Jr, Whitfield GK, Porti D, Kourides IA. The human thyrotropin beta-subunit gene differs in 5' structure from murine TSH-beta genes. DNA. 1988;7(10):691-9.

21. Naylor SL, Sakaguchi AY, McDonald L, Todd S, Lalley PA, Shows TB, et al. Mapping thyrotropin beta subunit gene in man and mouse. Somat Cell Mol Genet. 1986;12(3):307-11.
22. Everts-van der Wind A, Larkin DM, Green CA, Elliott JS, Olmstead CA, Chiu R, et al. A high-resolution whole-genome cattle-human comparative map reveals details of mammalian chromosome evolution. Proc Natl Acad Sci U S A. 2005 Dec 20;1O2(51):18526-31.

23. Yanga X, McGraw RA, Su X, Katakam P, Grosse WM, Li OW, et al. Canine thyrotropin beta-subunit gene: cloning and expression in Escherichia coli, generation of monoclonal antibodies, and transient expression in the Chinese hamster ovary cells. Domest Anim Endocrinol. 2000;18(4):363-78.

24. Geven EJ, Nguyen NK, van den Boogaart M, Spanings FA, Flik G, Klaren PH. Comparative thyroidology: thyroid gland location and iodothyronine dynamics in Mozambique tilapia (Oreochromis mossambicus Peters) and common carp (Cyprinus carpio L.). J Exp Biol. 2007;210(Pt 22):4005-15.

25. Sohn YC, Yoshiura Y, Suetake H, Kobayashi M, Aida K. Isolation and characterization of the goldfish thyrotropin beta subunit gene including the 5'-flanking region. Gen Comp Endocrinol. 1999;115(3):463-73. 